\title{
Interactions of Oxide Surfaces with Water Revealed with Solid-State NMR Spectroscopy
}

Junchao Chen, ${ }^{1,} \uparrow$ Michael A. Hope,${ }^{2,} \uparrow$ Zhiye Lin, ${ }^{1}$ Meng Wang, ${ }^{3}$ Tao Liu, ${ }^{2}$ David M. Halat, ${ }^{2}$ Yujie Wen, ${ }^{1}$ Teng Chen, ${ }^{1}$ Xiaokang Ke, ${ }^{1}$ Pieter C. M. M. Magusin, ${ }^{2}$ Weiping Ding, ${ }^{1}$ Xifeng Xia, ${ }^{4}$ Xin-Ping Wu, ${ }^{5, *}$ Xue-Qing Gong, ${ }^{5}$ Clare P. Grey, ${ }^{2, *}$ and Luming Peng ${ }^{1, *}$

${ }^{1}$ Key Laboratory of Mesoscopic Chemistry of MOE and Collaborative Innovation Center of Chemistry for Life Sciences, School of Chemistry and Chemical Engineering, Nanjing University, 163 Xianlin Road, Nanjing 210023, China.

${ }^{2}$ Department of Chemistry, University of Cambridge, Lensfield Road, Cambridge CB2 1EW, UK.

${ }^{3}$ College of Chemistry and Molecular Engineering (CCME), Peking University, Beijing 100871, China.

${ }^{4}$ Analysis and Testing Center, Nanjing University of Science and Technology, Nanjing 210094, China.

${ }^{5}$ Key Laboratory for Advanced Materials, Centre for Computational Chemistry and Research Institute of Industrial Catalysis, East China University of Science and Technology, 130 Meilong Road, Shanghai 200237, China. 


\begin{abstract}
Hydrous materials are ubiquitous in the natural environment and efforts have previously been made to investigate the structures and dynamics of hydrated surfaces for their key roles in various chemical and physical applications, with the help of theoretical modelling and microscopy techniques. However, an overall atomic-scale understanding of the water-solid interface, including the effect of water on surface ions, is still lacking. Herein, we employ ceria nanorods with different amounts of water as an example and demonstrate a new approach to explore the water-surface interactions by using solid-state NMR in combination with density functional theory. NMR shifts and relaxation time analysis provide detailed local structure of oxygen ions and the nature of water motion on the surface: the amount of molecularly adsorbed water decreases rapidly with increasing temperature (from room temperature to $150{ }^{\circ} \mathrm{C}$ ), whereas hydroxyl groups are stable up to $150{ }^{\circ} \mathrm{C}$; dynamic water molecules are found to instantaneously coordinate to the surface oxygen ions. The applicability of dynamic nuclear polarization for selective detection of surface oxygen species is also compared to conventional NMR with surface selective-labeling: the optimal method depends on the feasibility of enrichment and the concentration of protons in the sample. These results provide new insight into the interfacial structure of hydrated oxide nanostructures which is important for relevant applications.
\end{abstract}




\section{INTRODUCTION}

Water, the most pervasive molecule on earth, ${ }^{1}$ is involved in numerous chemical and physical processes on the surfaces of oxides, such as heterogeneous and homogeneous catalysis, ${ }^{2,3}$ photocatalysis, ${ }^{4}$ electrocatalysis, ${ }^{5}$ geochemistry, ${ }^{6}$ atmospheric chemistry, ${ }^{7}$ and corrosion. ${ }^{8}$ Hence, the interactions between oxide surfaces and water have long been the subject of study in both industry and academia. Determining the structure of an interface is vital to understand the interactions between the oxide surface and water; however, owing to the presence of surface defects and the dynamics of interfacial water, challenges exist in determining accurate atomic-level geometries and electronic structures at water-oxide interfaces. ${ }^{9}$ Recent insights into the behavior of water have been gained mostly with the help of microscopy-based techniques and density functional theory (DFT) calculations. ${ }^{10,11}$ Interfacial water molecules are found to associate with oxide surfaces via various interactions, including electrostatics, charge transfer and hydrogen bonding. ${ }^{11,12}$ Molecularly adsorbed water $\left(\mathrm{H}_{2} \mathrm{O}\right)$ molecules can behave as isolated monomers, dimers, greater multimers, two-dimensional bilayers, and three-dimensional clusters, as well as in different ice configurations. ${ }^{7}$ Surface hydroxyl groups, formed from dissociation of $\mathrm{H}_{2} \mathrm{O}$ molecules, ${ }^{13}$ can cause reconstructions of oxide surfaces, ${ }^{14-16}$ and participate in catalytic reactions under certain circumstances. ${ }^{2}$ Insights have been gained with microscopy-based techniques, however these are often performed at ultrahigh vacuum conditions and the results are not necessarily indicative of the surface structures under ordinary pressure (e.g. in real catalysis); in addition, it is impossible to obtain information on the whole sample with such methods, let alone to acquire quantitative details. ${ }^{17}$ Other spectroscopic techniques that can be used to investigate hydrated surfaces also require high or ultrahigh vacuum, such as inelastic electron tunneling spectroscopy ${ }^{9}$ and infrared reflection absorption spectroscopy. ${ }^{18}$ Therefore, it is urgent to develop alternative methodologies in order to gain deeper understanding of the water-oxide interfaces. 
Solid-state NMR spectroscopy is a powerful technique that can monitor local structural information for solids ${ }^{19-21}$ and complement traditional surface-science approaches. It has previously been shown that the $1^{\text {st }}$, $2^{\text {nd }}$ and $3^{\text {rd }}$ (sub-)surface layer oxygen species, as well as surface hydroxyl groups, can be distinguished from bulk oxygen in the ${ }^{17} \mathrm{O}$ solid-state NMR spectrum of pristine ${ }^{17} \mathrm{O}$ labeled ceria (111) surfaces, and identified using DFT calculations. ${ }^{22,23}$ Dynamic nuclear polarization (DNP), which involves transferring spin polarization from electrons (typically added to the system in the form of organic radicals) to nuclei on a solid surface (e.g., ${ }^{17} \mathrm{O}$ ), ${ }^{24}$ has also been used to achieve surface-selective enhancement of the ${ }^{17} \mathrm{O}$ NMR of $\mathrm{CeO}_{2}$ nanoparticles. ${ }^{25}$ In a direct DNP experiment, the nucleus of interest is directly hyperpolarized and observed, whereas in indirect DNP ${ }^{1} \mathrm{H}$ nuclei are first hyperpolarized and the ${ }^{1} \mathrm{H}$ polarization diffuses throughout the sample before cross polarization is used to transfer the polarization to the nucleus of interest. This greatly enhances the NMR signal because the gyromagnetic ratio, and hence the equilibrium polarization, of the electron is significantly higher than that of nuclei.

Our previous studies using this methodology of surface selective ${ }^{17} \mathrm{O}$ labeling and solid-state NMR spectroscopy mainly focus on the detection of surface oxygen species and hydroxyls. ${ }^{15,22,26,27}$ In this work, we use ceria nanorods with different water coverages, which are dominated by the (111) surface and have large specific surface areas, as a model system to study oxide-water interactions, considering that ceria is well-known as a catalyst or an active catalyst support for reactions such as water splitting, ${ }^{28}$ the water-gas shift reaction, ${ }^{29}$ oxidative dehydrogenation, ${ }^{30}$ preferential oxidation of $\mathrm{CO},{ }^{31}$ and automotive three-way catalysis. ${ }^{32}$ The utilization of conventional and DNP-enhanced ${ }^{17} \mathrm{O}$ NMR is complemented by ${ }^{1} \mathrm{H}$ solid-state NMR spectra, which are used to quantify the coverage of molecular and dissociated water molecules; combining these results with DFT calculations, we obtain an overall picture of ceria (111) surface with different water coverages and hence a deeper comprehension on the water-surface interactions. Furthermore, 
in order to investigate the optimal strategy for surface NMR investigations of hydrated surfaces, we consider both direct and indirect DNP and compare them with surface selective isotopic labeling.

\section{RESULTS AND DISCUSSION}

The XRD pattern (Figure S1) of the ceria nanoparticles shows that the ceria sample crystallizes with a fluorite structure (JCPDS No. 34-0394). HRTEM images (Figure S2) reveal that the rods of $100-200 \mathrm{~nm}$ length are dominated by the (111) surface but are filled with mesopores $(2-25 \mathrm{~nm})$. The BET specific surface area of the ceria nanorods was determined to be $110.9 \mathrm{~m}^{2} \cdot \mathrm{g}^{-1}$ (Figure S3A), and the size distribution of the mesopores (Figure S3B) is consistent with the HRTEM determination. XPS, ICP-MS and elemental analysis information together demonstrate that $\mathrm{Na}^{+}$or $\mathrm{NO}_{3}{ }^{-}$residues are not detectable on the surface of as-synthesized ceria nanorods (Figure S4 and Table S1). Furthermore, the amount of surface oxygen vacancies is quantified as $0.8 \%$ for a representative sample (NRs-100) according to the Raman spectrum (Figure S5 and Note S1), and the influence of oxygen vacancies is therefore not considered for the ceria nanorods dried below $100{ }^{\circ} \mathrm{C}$.

The ${ }^{17} \mathrm{O}$ solid-state NMR spectrum for ceria nanorods enriched with ${ }^{17} \mathrm{O}_{2}$ at $300{ }^{\circ} \mathrm{C}\left(\mathrm{NRs}-{ }^{17} \mathrm{O}_{2}\right.$, Figure S6) shows a large signal of bulk oxygen at 877 ppm and relatively sharp signals at 1030, 920, and 829 ppm, which are assigned to the oxygen species in the $1^{\text {st }}, 2^{\text {nd }}$, and $3^{\text {rd }}$ (sub-)surface layers of ceria (111), respectively, in good agreement with the previous results. ${ }^{22}$ This confirms that the surfaces, both external to the nanorods and in the mesopores, are clean crystalline (111) facets, corroborating the TEM analyses.

To investigate the effect of water on the surface environments, samples of ceria nanorods were exposed to $\mathrm{H}_{2}{ }^{17} \mathrm{O}$ followed by heat treatment at temperatures ranging from room temperature (RT) to $150{ }^{\circ} \mathrm{C}$, and their 
${ }^{17} \mathrm{O}$ NMR spectra were recorded (Figure 1; denoted NRs-T, where T is the heat treatment temperature). For NRs-100 and NRs-150, the shifts are similar to the ${ }^{17} \mathrm{O}_{2}$ enriched sample, with the oxygen species in the $1^{\text {st }}$, $2^{\text {nd }}$, and $3^{\text {rd }}$ (sub-)surface layers being observed at 1020, 920, and $833 \mathrm{ppm}$, respectively; the signal of bulk oxygen ions at $877 \mathrm{ppm}$ is much less intense than that of the ${ }^{17} \mathrm{O}_{2}$ enriched sample, which is due to the greater surface selectivity of the lower temperature $\mathrm{H}_{2}{ }^{17} \mathrm{O}$ enrichment. Hydroxyl groups can also be observed at $280 \mathrm{ppm}$, although the intensity is low due to a distribution of environments with large quadrupolar coupling constants. In contrast, the RT enriched sample exhibits notable differences in the ${ }^{17} \mathrm{O}$ spectrum and resonances for the (sub-)surface oxygen species are now observed at 1010, 894 and 845 ppm, while the signal of the bulk oxygen ions are unchanged in frequency. Due to the broad linewidth and low intensity of ${ }^{17} \mathrm{O}$ signals for hydroxyl sites, no obvious change in in the resonant frequency can be observed in these samples. As the drying temperature increases, the spectrum evolves towards that expected for a pristine (111) surface and in particular the $894 \mathrm{ppm}$ signal progressively shifts towards $920 \mathrm{ppm}$. Furthermore, the sample which was heat treated at $100{ }^{\circ} \mathrm{C}$ and then re-enriched with $\mathrm{H}_{2}{ }^{17} \mathrm{O}$ at RT (NRs-100 $\rightarrow$ RT) exhibits a similar spectrum to NRs-RT, indicating that the surface structure of the sample dried at $100{ }^{\circ} \mathrm{C}$ restores after adding more $\mathrm{H}_{2} \mathrm{O}$. 


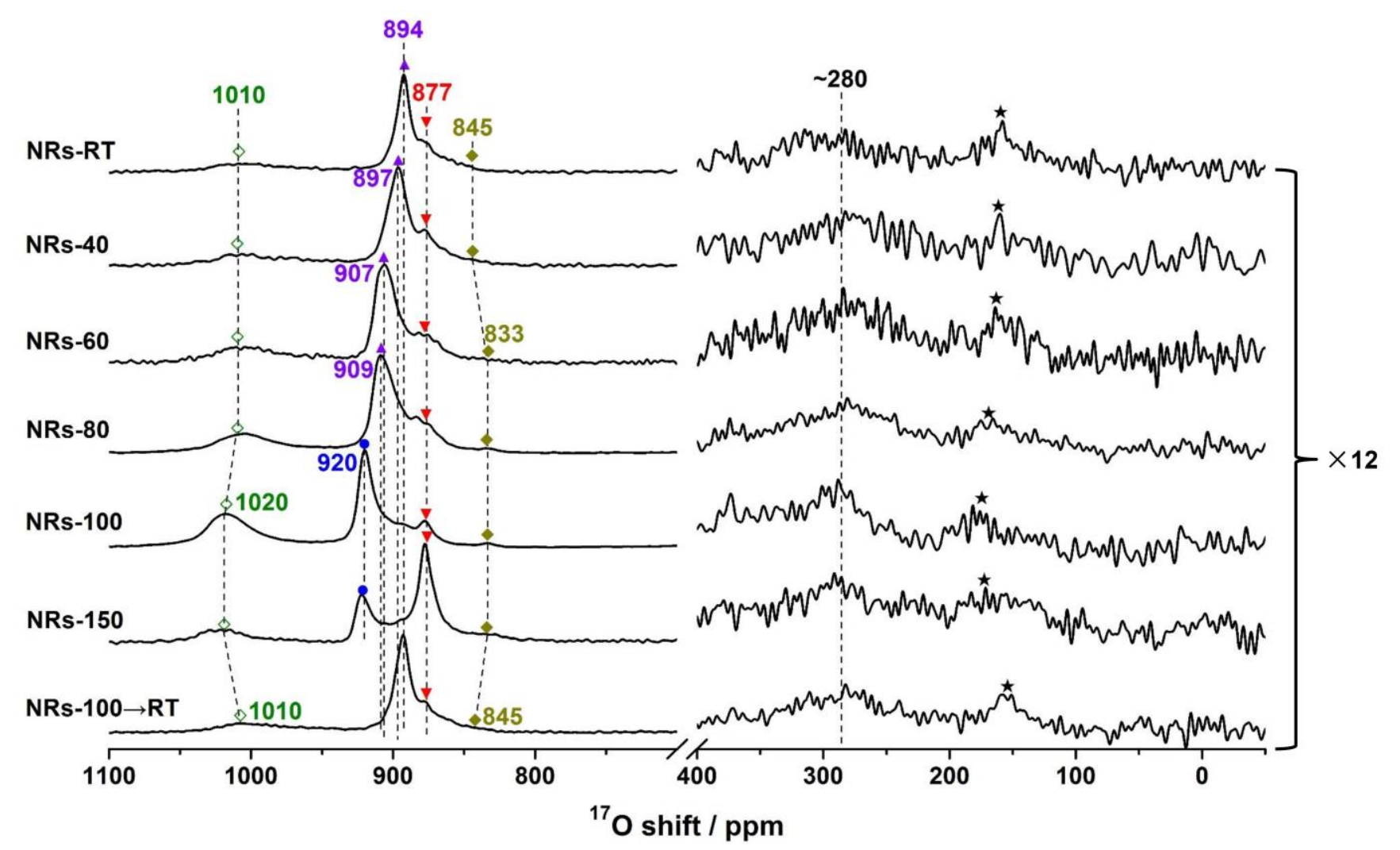

Figure $1 .{ }^{17} \mathrm{O}$ solid-state NMR spectra of ceria NRs respectively enriched from RT to $150{ }^{\circ} \mathrm{C}$ with $\mathrm{H}_{2}{ }^{17} \mathrm{O}$. The spectra were recorded at a spinning speed of $20.0 \mathrm{kHz}$ for all samples with a $0.5 \mathrm{~s}$ recycle delay. A rotor synchronized Hahn-echo pulse sequence $(\pi / 2-\tau-\pi-\tau$-acquisition, $\tau=1$ rotor-period $)$ with ${ }^{1} \mathrm{H}$ decoupling was applied. Asterisks denote spinning sidebands. The $1^{\text {st }}$ and $2^{\text {nd }}$ layer oxygen environments for the unhydrated surface are denoted with green open diamonds and blue circles respectively. The purple triangles represent the indistinguishable $1^{\text {st }}$ and $2^{\text {nd }}$ layer oxygen environments of the hydrated surface. The bulk and $3^{\text {rd }}$ sub-surface layer oxygen environments are denoted with inverted red triangles and gold-filled diamonds, respectively. All the spectra are scaled by matching the most intense signal.

These spectral variations are likely due to the influence of surface water, which can be progressively removed with increasing heat treatment temperature. To test this hypothesis, quantitative ${ }^{1} \mathrm{H}$ single pulse NMR spectra were measured (Figure 2A), for which the integrated ${ }^{1} \mathrm{H}$ NMR intensity clearly decreases with increasing drying temperature. Deconvolution of the spectra (Figure S7) reveals a resonance at $5.4 \mathrm{ppm}$ 
from molecularly adsorbed $\mathrm{H}_{2} \mathrm{O}$ molecules, ${ }^{33}$ broad signals between $3.5-16$ ppm (labeled as $~ 8.4$ ppm) assigned to bridging hydroxyl groups $\left(-\mathrm{OH}_{\mathrm{B}} \mathrm{S}\right.$, Figure $\left.2 \mathrm{~A}\right)$ which are formed by protonating three-coordinated oxygen $\left(\mathrm{O}_{3 \mathrm{C}}\right)$ ions, and a well-defined peak at $1.6 \mathrm{ppm}$ ascribed to terminal hydroxyl groups $\left(-\mathrm{OH}_{\mathrm{T}} \mathrm{s}\right.$, Figure $\left.2 \mathrm{~A}\right)$ which form when a water molecule bonds to a seven-coordinated cerium $\left(\mathrm{Ce}_{7 \mathrm{C}}\right)$ ion then loses a proton; ${ }^{33,34}$ the deconvoluted spectral parameters are listed in Table S2. These assignments are based on our DFT calculations (see below), which are consistent with previous results. ${ }^{33,34}$ It should be noted that the wide linewidth of the $-\mathrm{OH}_{\mathrm{B}}$ signal is due to a broad distribution of hydrogen bonding environments of the $-\mathrm{OH}_{\mathrm{B}}$, whereas the sharp $-\mathrm{OH}_{\mathrm{T}}$ signal indicates a well-defined chemical environment of the $-\mathrm{OH}_{\mathrm{T}}$. The observation of these hydroxyl groups in ${ }^{1} \mathrm{H}$ NMR is consistent with ${ }^{17} \mathrm{O}$ NMR results shown in Figure 1, indicating that water dissociation occurs on the surface of ceria nanorods.

By combining the integrated ${ }^{1} \mathrm{H}$ intensities, the BET specific surface area data and the sample masses, concentrations of the molecular $\left(\mathrm{H}_{2} \mathrm{O}\right)$ and dissociated water molecule $\left(-\mathrm{OH}_{\mathrm{T}}\right.$ and $\left.-\mathrm{OH}_{\mathrm{B}}\right)$ were determined, which are shown as a function of the drying temperature in Figure 2B (see also Figure S8 and Table S3). Interestingly, the concentrations of hydroxyl species $\left(-\mathrm{OH}_{\mathrm{T}}\right.$ and $\left.-\mathrm{OH}_{\mathrm{B}}\right)$ are unaffected by the thermal treatment up to $150{ }^{\circ} \mathrm{C}$, remaining at around 2.30 groups per surface unit respectively, whereas the concentration of $\mathrm{H}_{2} \mathrm{O}$ decreases from RT to $100{ }^{\circ} \mathrm{C}$. These quantifications illustrate that hydroxyl species formed on ceria (111) surfaces from water dissociation are stable under vacuum at moderate temperatures, while molecularly adsorbed water molecules are readily removed. The variations of the amount of water molecularly adsorbed may be associated with the evolution of the ${ }^{17} \mathrm{O}$ signals for the (sub-)surface layer oxygen ions; in particular, a very low concentration of $\mathrm{H}_{2} \mathrm{O}$ was determined for the samples enriched at 100 and $150{ }^{\circ} \mathrm{C}$, which is consistent with the similarity of the ${ }^{17} \mathrm{O}$ spectra for these samples to that of pristine (111) surfaces. ${ }^{22}$ Note that the thermal treatment at $300{ }^{\circ} \mathrm{C}$ before exposure to $\mathrm{H}_{2}{ }^{17} \mathrm{O}$ introduces a significant 
amount of surface oxygen vacancies (6 \% from Raman analysis, see Figure S9); the water molecules introduced during enrichment can dissociate at these vacancy sites and form two surface $-\mathrm{OH}_{\mathrm{B}}$ groups per water molecule, ${ }^{34}$ leading to the larger concentrations of $-\mathrm{OH}_{\mathrm{B}}$ groups than $-\mathrm{OH}_{\mathrm{T}}$ for the $\mathrm{H}_{2}{ }^{17} \mathrm{O}$ enriched samples. In contrast, the ${ }^{17} \mathrm{O}_{2}$ enriched sample $\mathrm{NRs}-{ }^{17} \mathrm{O}_{2}$, which was not exposed to water, exhibits approximately equal concentration of $-\mathrm{OH}_{\mathrm{B}}$ and $-\mathrm{OH}_{\mathrm{T}}(0.23$ and 0.27 groups per surface unit respectively, see Table S3).
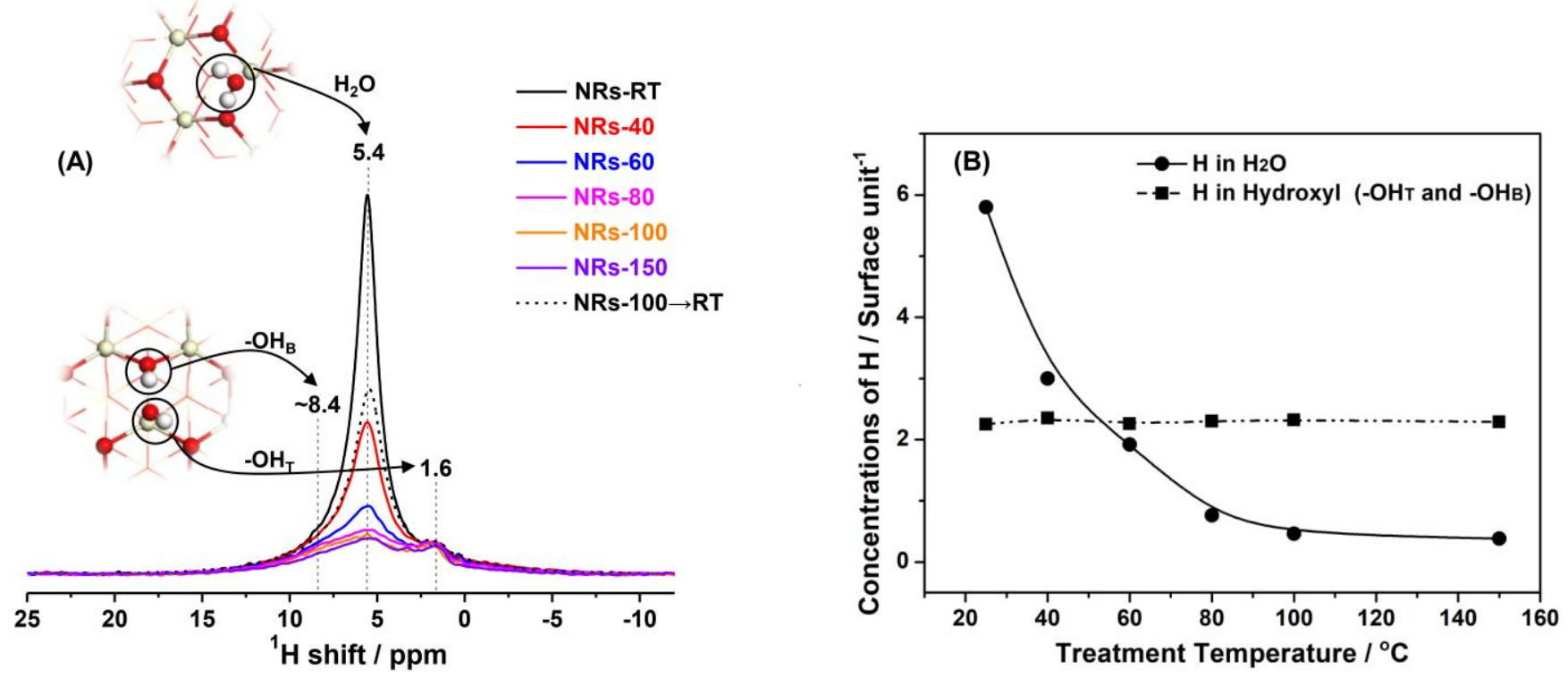

Figure 2. (A) ${ }^{1} \mathrm{H}$ Solid-State NMR spectra of ceria nanorods enriched from RT to $150{ }^{\circ} \mathrm{C}$ with $\mathrm{H}_{2}{ }^{17} \mathrm{O}$ and (B) the concentrations of protonated species $\left(-\mathrm{OH}_{\mathrm{T}},-\mathrm{OH}_{\mathrm{B}}\right.$ and $\left.\mathrm{H}_{2} \mathrm{O}\right)$ on the surfaces of ceria nanorods. The surface unit is the same as used in the calculations below, $[1 \overline{1} 0] \times[10 \overline{1}]=51.3 \AA^{2}$, see e.g. Figure 5. Each surface unit contains four surface Ce ions and four surface $\mathrm{O}$ ions. The ${ }^{1} \mathrm{H}$ single pulse NMR measurements were carried out at a spinning speed of $20.0 \mathrm{kHz}$ with a recycle delay of $4.0 \mathrm{~s}$. For the inserted sketches in Figure 2A, cerium, hydrogen and oxygen ions are off-white, white and red, respectively; this color scheme is used throughout the paper.

Although we are able to detect resonances due to $\mathrm{H}_{2} \mathrm{O}$ with ${ }^{1} \mathrm{H}$ NMR (Figure 2A), the corresponding ${ }^{17} \mathrm{O}$ resonances which would appear at $\sim 0 \mathrm{ppm}$ could not be observed in the conventional ${ }^{17} \mathrm{O}$ NMR spectra 
(Figure 1). The ${ }^{1} \mathrm{H} \rightarrow{ }^{17} \mathrm{O}$ indirect DNP NMR spectrum was therefore recorded for NRs-RT (Figure 3): without microwave irradiation, no signals can be observed in the ${ }^{17} \mathrm{O}$ spectrum of NRs-RT; however, upon microwave irradiation, two broad resonances centered at 220 and 0 ppm were observed and can be assigned to surface hydroxyl groups and $\mathrm{H}_{2} \mathrm{O}$ molecules, respectively. Although the DNP enhancement cannot be calculated due to the lack of signal in the microwave off spectrum, this enhancement is clearly significant; furthermore, as previously demonstrated, ${ }^{25}$ the indirect ${ }^{17} \mathrm{O}$ DNP NMR spectrum is selective for oxygen ions directly bonded to protons (i.e., $\mathrm{H}_{2} \mathrm{O}$ and hydroxyl species), and the $1^{\text {st }}, 2^{\text {nd }}$, and $3^{\text {rd }}$ layer (sub-)surface environments observed in the direct excitation ${ }^{17} \mathrm{O}$ NMR spectra cannot be detected. The difference in shift for the hydroxyl groups between the DNP ( 220 ppm) and conventional ${ }^{17} \mathrm{O}$ spectra $(\sim 280 \mathrm{ppm})$ is ascribed to the difference in temperature ( $100 \mathrm{~K}$ for DNP, c.f. room temperature), which can have a significant effect on the dynamics and hydrogen bonding of the surface water and hydroxyl groups. However, the fact that the signal for molecular water is observed at $\sim 0 \mathrm{ppm}$, the isotropic ${ }^{17} \mathrm{O}$ chemical shift for water, rules out a significant second-order quadrupolar shift which would contribute more than $-100 \mathrm{ppm}$ to the observed shift, according to previously reported experimental quadrupolar constants of larger than $5.8 \mathrm{MHz}$ for ice; ${ }^{35}$ this indicates that there is significant motion of the surface water molecules, which averages the ${ }^{17} \mathrm{O}$ quadrupolar tensor, even at $100 \mathrm{~K}$. The absence of the signal for surface $\mathrm{H}_{2} \mathrm{O}$ at $\sim 0 \mathrm{ppm}$ and the low intensity of the signals for the hydroxyl groups in the conventional ${ }^{17} \mathrm{O}$ NMR spectra (and the low-temperature microwave off spectrum) are probably due to the large widths of these signals which lead to lower peak heights.
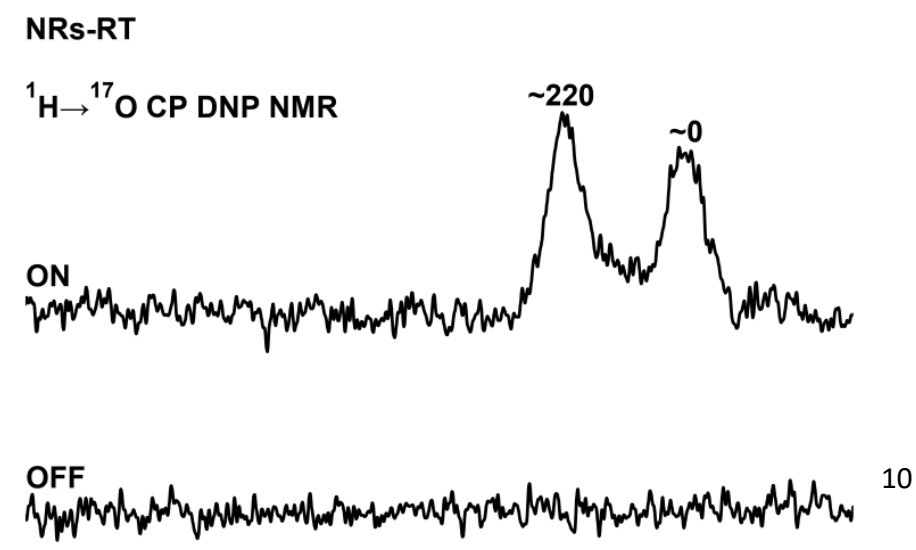
Figure 3. The indirect DNP ${ }^{17} \mathrm{O}$ NMR spectra, with and without microwave irradiation of ceria NRs-RT impregnated with TEKPol in TCE, recorded at a spinning speed of $12.5 \mathrm{kHz}$ with a recycle delay of $4.0 \mathrm{~s}$ and a contact time of $500.0 \mu \mathrm{s}^{25}$ for the ${ }^{1} \mathrm{H} \rightarrow{ }^{17} \mathrm{O}$ cross polarization.

Rotational-echo double-resonance (REDOR) NMR is a technique for investigating the proximity of hetero-nuclei under MAS conditions; $;{ }^{36} \mathrm{H} \rightarrow{ }^{17} \mathrm{O}$ REDOR experiments were, therefore, performed in order to confirm the correlation between (sub-)surface oxygen species and water on the ceria surfaces. In a REDOR experiment, ${ }^{17} \mathrm{O}$ spectra with and without reintroduction of the ${ }^{1} \mathrm{H} \rightarrow{ }^{17} \mathrm{O}$ dipolar coupling are recorded; the difference of the two spectra then reveals signals from ${ }^{17} \mathrm{O}$ ions in the vicinity of ${ }^{1} \mathrm{H}$ nuclei, which dephase under the recoupling. ${ }^{37,38}$ The room temperature ${ }^{1} \mathrm{H} \rightarrow{ }^{17} \mathrm{O}$ REDOR experiment for NRs-RT, recorded with 12 rotor-periods of recoupling (Figure 4A), does not show any signals. This is ascribed to the fast motion of surface water at room temperature which averages out the ${ }^{1} \mathrm{H} \rightarrow{ }^{17} \mathrm{O}$ dipolar coupling, ${ }^{9,39}$ i.e., eliminates the REDOR effect. The low temperature $(190 \mathrm{~K}){ }^{1} \mathrm{H} \rightarrow{ }^{17} \mathrm{O}$ REDOR experiment (Figure 4B), on the other hand, exhibits a minor REDOR effect for signals centred at $\sim 830 \mathrm{ppm}$ and $\sim 1050 \mathrm{ppm}$, suggesting these ${ }^{17} \mathrm{O}$ signals are close to surface proton or related species, although there is likely to still be significant motional averaging of the dipolar coupling.

(A)

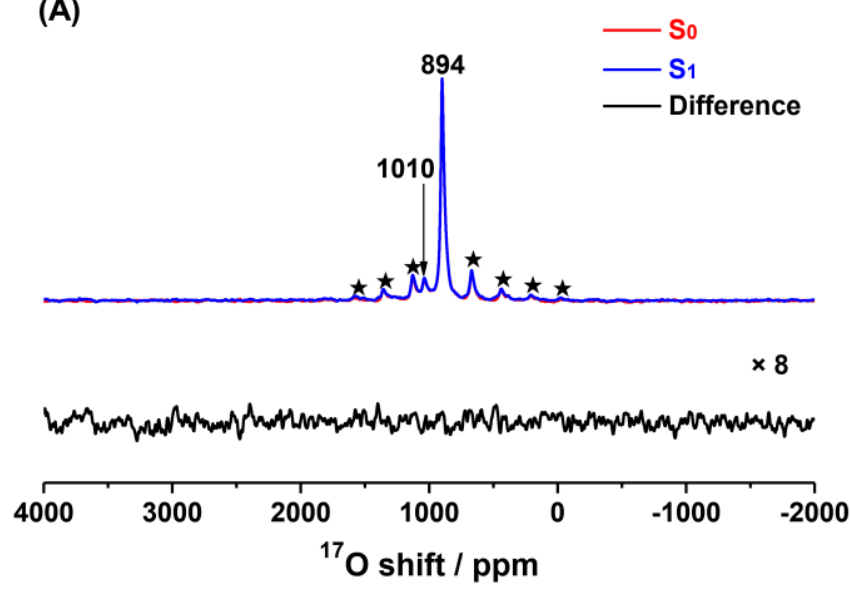

(B)

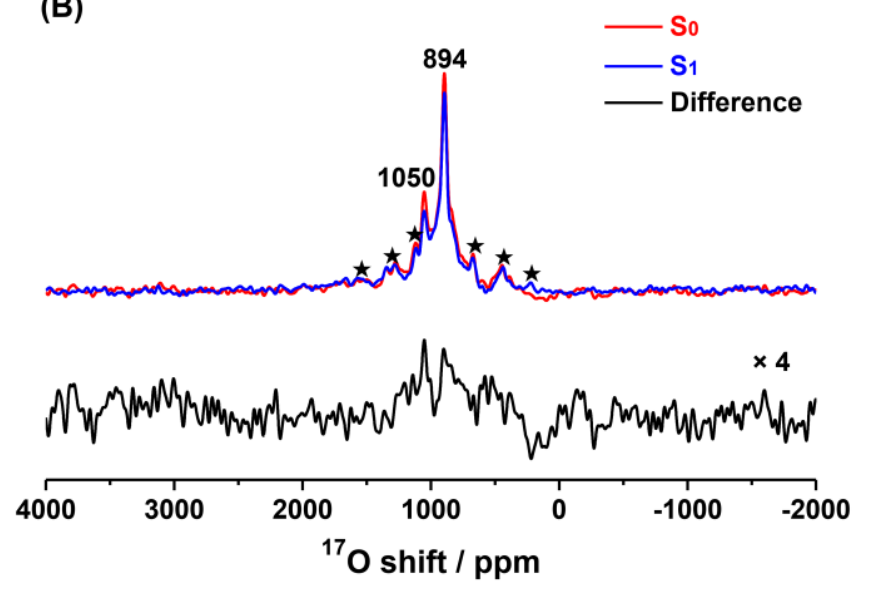


Figure 4. (A) Room temperature (RT) and (B) low temperature (LT, $190 \mathrm{~K}){ }^{1} \mathrm{H} \rightarrow{ }^{17} \mathrm{O}$ REDOR NMR spectra of ceria NRs-RT. The RT and LT measurements were recorded at a spinning speed of $12.5 \mathrm{kHz}$, with 12 rotor periods of recoupling and a recycle delay of $0.1 \mathrm{~s} . \mathrm{S}_{0}$ and $\mathrm{S}_{1}$ correspond to the REDOR spectra recorded without and with recoupling respectively. Asterisks denote spinning sidebands.

To investigate the adsorption configurations and energies of water molecules at the ceria (111) surface, DFT calculations were conducted on hydrated ceria (111) surfaces with between 1/4 monolayer and one monolayer of molecularly and/or dissociatively adsorbed water molecules (Figures 5) ; the $\mathrm{O}_{\mathrm{M} 3 \mathrm{D} 1}$ model was also previously reported by Kropp et al. ${ }^{40}$ For all the hydrated ceria (111) surfaces considered, the calculated average adsorption energies $\left(E_{a d s}^{a v g}\right)$ of $\mathrm{H}_{2} \mathrm{O}$ are negative (ca. $-0.5--0.7 \mathrm{eV}$ ), indicating the favorable adsorption of water on ceria (111) surface. $E_{a d s}^{a v g}$ is comparable for molecular and dissociative adsorption, which is consistent with the experimentally established concurrent presence of both $\mathrm{H}_{2} \mathrm{O}$ and hydroxyl groups. 


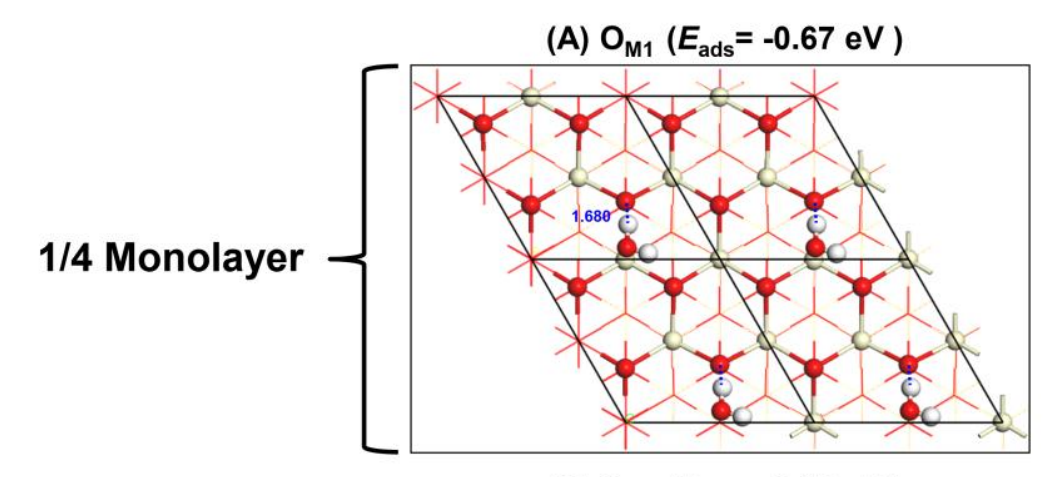

(C) $\mathrm{O}_{\mathrm{M} 2}\left(E_{\mathrm{ads}}=-0.70 \mathrm{eV}\right)$

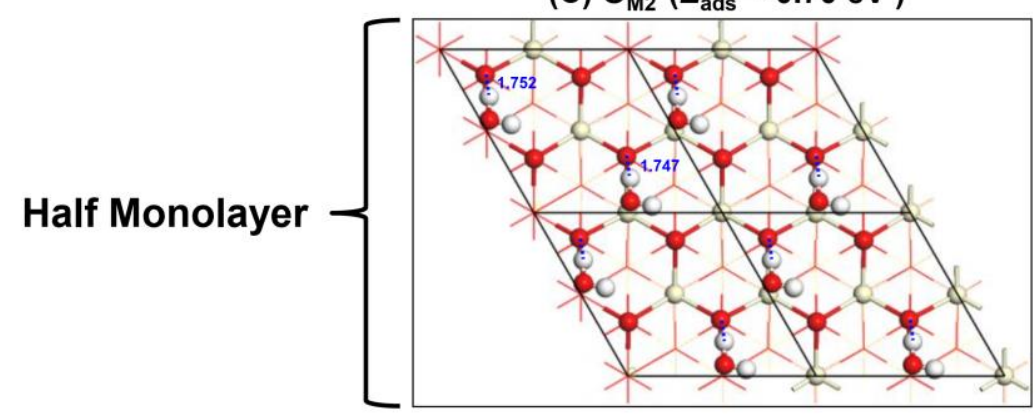

$(E) O_{M 4}\left(E_{\text {ads }}=-0.74 \mathrm{eV}\right)$

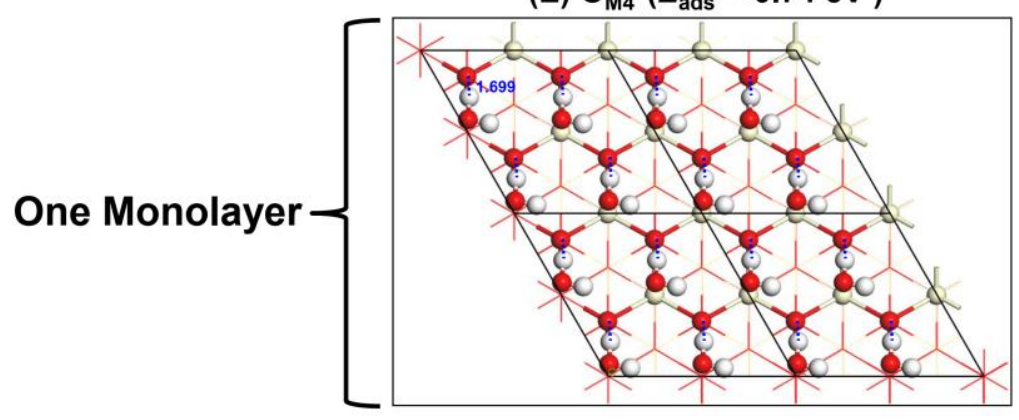

(B) $\mathrm{O}_{\mathrm{D} 1}\left(E_{\mathrm{ads}}=-\mathbf{0 . 6 0 \mathrm { eV } )}\right.$

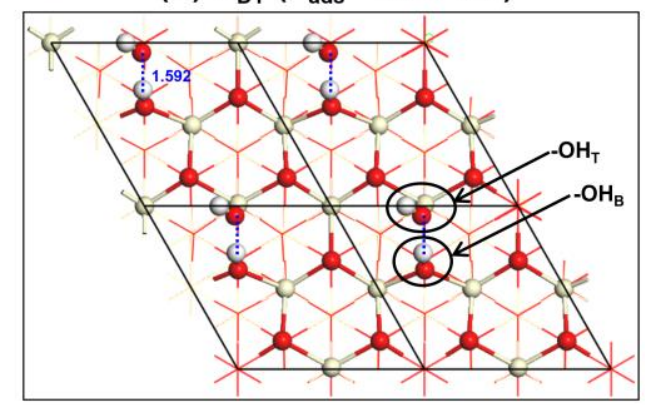

(D) $\mathrm{O}_{\mathrm{D} 2}\left(E_{\mathrm{ads}}=-0.52 \mathrm{eV}\right)$

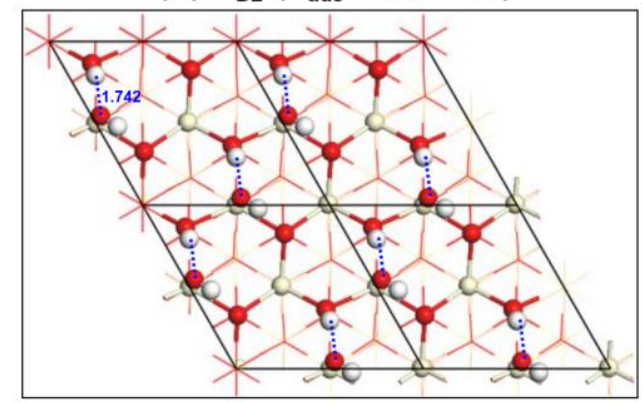

(F) $\mathrm{O}_{\mathrm{M} 3 \mathrm{D} 1}\left(E_{\mathrm{ads}}=-\mathbf{0 . 7 1 \mathrm { eV }}\right)$

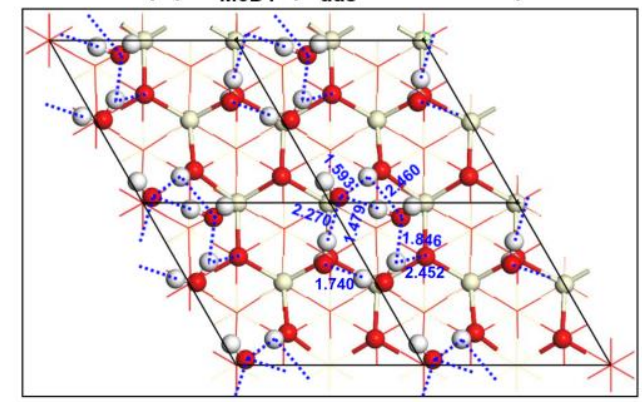

Figure 5. Top views of hydrated ceria (111) surfaces at the water coverages of $1 / 4$ monolayer (A, B), half monolayer $(\mathrm{C}, \mathrm{D})$, and one monolayer $(\mathrm{E}, \mathrm{F}) . \mathrm{O}_{\mathrm{M} x \mathrm{Dy}}$ denotes a model with $x$ molecular water molecules and y dissociated water molecules per surface unit. Red, off-white and white spheres represent oxygen, hydrogen and cerium ions, respectively. Blue dashed lines denote hydrogen bonds, for which the hydrogen bond distances are also given.

The DFT calculations show that molecular $\mathrm{H}_{2} \mathrm{O}$ adsorption is preferred at the surface $\mathrm{Ce}_{7 \mathrm{C}}$ sites with one proton of water hydrogen bonding to the nearby $\mathrm{O}_{3 \mathrm{C}}$ ion $\left(\mathrm{O}_{\mathrm{M} 1}\right.$ in Figure $\left.5 \mathrm{~A}\right)$. The adsorbed water molecule can also dissociate by transferring one proton to the nearby $\mathrm{O}_{3 \mathrm{C}}$ ion, generating two hydroxyls (one $-\mathrm{OH}_{\mathrm{B}}$ and one $\left.-\mathrm{OH}_{\mathrm{T}}\right)$ which are associated with each other by a hydrogen bond $\left(\mathrm{O}_{\mathrm{D} 1}\right.$ in Figure $\left.5 \mathrm{~B}\right)$; these results 
are consistent with previous theoretical studies. ${ }^{28,40}$ The ${ }^{1} \mathrm{H}$ chemical shifts were calculated for model $\mathrm{O}_{\mathrm{D} 1}$ (Table S4); these corroborate the assignments of the $-\mathrm{OH}_{\mathrm{B}}$ and $-\mathrm{OH}_{\mathrm{T}}$ resonances in the experimental ${ }^{1} \mathrm{H}$ spectra: if the calculated $-\mathrm{OH}_{\mathrm{T}}$ shift is aligned with the experimental shift of $1.6 \mathrm{ppm}$, then the calculated $-\mathrm{OH}_{\mathrm{B}}$ shift is $7.8 \mathrm{ppm}$, which is in reasonable agreement with the experimental shift of $\sim 8.4 \mathrm{ppm}$, especially given the width of this signal caused by a distribution of hydrogen bonding.

To gain further insights from the ${ }^{17} \mathrm{O}$ NMR spectra, the ${ }^{17} \mathrm{O}$ NMR parameters (isotropic chemical shift, $\delta_{\text {iso }}$, quadrupolar parameter $\left(C_{\mathrm{Q}}\right.$ and $\left.\eta\right)$ and center of gravity, $\left.\delta_{\mathrm{CG}}\right)$ for the oxygen ions in the models $\mathrm{O}_{\mathrm{M} 1}, \mathrm{O}_{\mathrm{M} 2}$ and $\mathrm{O}_{\mathrm{M} 4}$ were also calculated using DFT (Figures S10 - S18 and Tables S5 $\left.-\mathrm{S} 7\right)$. The calculated shifts $\left(\delta_{\mathrm{CG}} \mathrm{S}\right)$ for $\mathrm{O}_{\mathrm{M} 1}, \mathrm{O}_{\mathrm{M} 2}$ and $\mathrm{O}_{\mathrm{M} 4}$ are compared to the data for oxygen ions at pristine ceria (111) surfaces (from our previous work, and the model is abbreviated as $\mathrm{O}_{\mathrm{M} 0}$ here) (Figure 6). ${ }^{22}$ On adsorption of water, the hydrogen bonding to an under-coordinated $1^{\text {st }}$ layer $\mathrm{O}_{3 \mathrm{C}}$ ion causes a decrease in the calculated ${ }^{17} \mathrm{O} \delta_{\mathrm{CG}} \mathrm{S}$ from 1033 ppm to $924-883 \mathrm{ppm}$, depending on the water concentrations. Concurrently, the ${ }^{17} \mathrm{O} \delta_{\mathrm{CG}} \mathrm{S}$ of the $2^{\text {nd }}$ layer oxygen ions decrease from $921 \mathrm{ppm}$ to $913-893 \mathrm{ppm}$, thus these two signals cannot be distinguished from each other, again in agreement with the single resonance observed at a lower frequency than $920 \mathrm{ppm}$ in the experimental spectra. Furthermore, the higher calculated ${ }^{17} \mathrm{O} \delta_{\mathrm{CG}} \mathrm{S}$ for the $3^{\text {rd }}$ layer oxygen environment of 868, 861 and $852 \mathrm{ppm}$ for $\mathrm{O}_{\mathrm{M} 1}, \mathrm{O}_{\mathrm{M} 2}$ and $\mathrm{O}_{\mathrm{M} 4}$ compared to $837 \mathrm{ppm}$ for $\mathrm{O}_{\mathrm{M} 0}$ is consistent with the higher experimental observed shift at $\sim 845 \mathrm{ppm}$ in a more hydrated sample than $833 \mathrm{ppm}$ in a relatively dry sample, although the shift is overestimated in the calculations. 


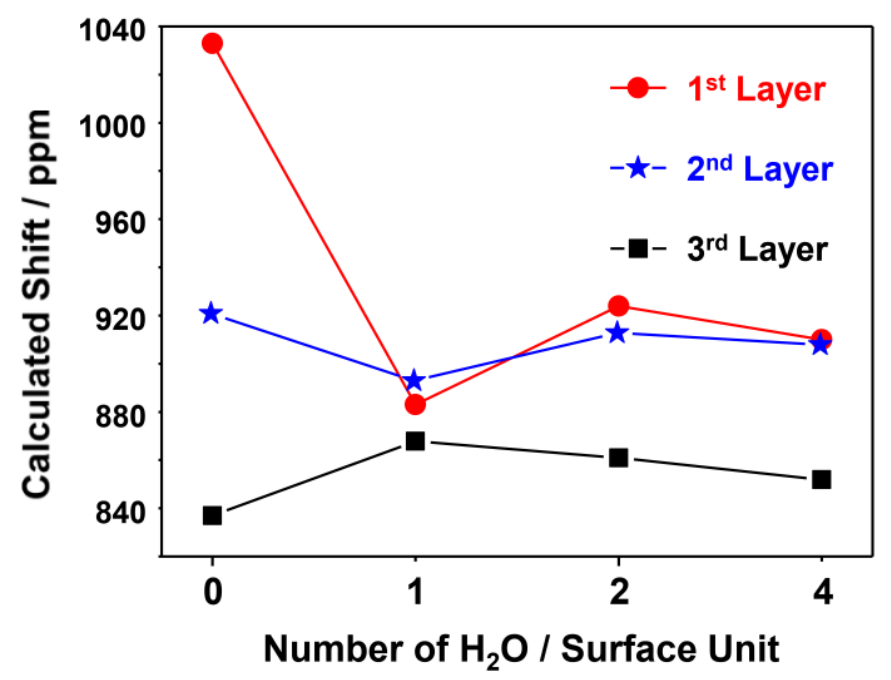

Figure 6. Calculated NMR shifts (center of gravity, $\delta_{\mathrm{CG}} \mathrm{s}$ ) of the oxygen ions in the $1^{\text {st }}, 2^{\text {nd }}$ and $3^{\text {rd }}$ (sub-)surface layer with 0,1,2 and 4 water molecules per surface unit (corresponding to the models $\mathrm{O}_{\mathrm{M} 0 \text {, }}$ $\mathrm{O}_{\mathrm{M} 1}, \mathrm{O}_{\mathrm{M} 2}$, and $\left.\mathrm{O}_{\mathrm{M} 4}\right)$. The shifts summarized in this figure are extracted from our previous work, ${ }^{22}$ Figures S12, S15 and S18, and Tables S5 - S7.

The calculations do not, however, reveal a clear trend in the ${ }^{17} \mathrm{O}$ shift of hydrated $1^{\text {st }}$ and $2^{\text {nd }}$ layer oxygen sites as a function of the water content to explain the increase in the shift of this signal in the experimental spectra with increasing drying temperature (Figure 1). Instead, we propose that the observed frequency is a weighted average of the chemical shifts with and without hydration, due to motion of the $\mathrm{H}_{2} \mathrm{O}$ molecules on the surface faster than the frequency separation of these environments $\left(6.5 \mathrm{kHz}\right.$ and $1.5 \mathrm{kHz}$ for the $1^{\text {st }}$ and $2^{\text {nd }}$ layer, respectively). After enrichment with $\mathrm{H}_{2}{ }^{17} \mathrm{O}$ and drying under vacuum at room temperature, the ${ }^{17} \mathrm{O}$ signal is observed at $894 \mathrm{ppm}$, which is consistent with a fully hydrated region of the sample. With increasing drying temperature, the amount of $\mathrm{H}_{2} \mathrm{O}$ on the surface decreases (as shown by ${ }^{1} \mathrm{H}$ NMR, Figure 2), so that these $1^{\text {st }}$ and $2^{\text {nd }}$ layer oxygen ions spend an increasing fraction of the time without coordination by $\mathrm{H}_{2} \mathrm{O}$ and hence experiencing a higher chemical shift, causing the fast motionally time-averaged frequency to increase. Unlike the variation of ${ }^{17} \mathrm{O}$ shifts, ${ }^{1} \mathrm{H}$ shifts do not show a change on the surface coverage of molecular water (Figure 2), which is presumably due to a combination of the small chemical shift range of 
${ }^{1} \mathrm{H}$ and the fact that although not every oxygen ion on the surface can be coordinated by water, every water molecule is coordinated to a surface oxygen ion since the coverage is less than a monolayer for all the samples studied.

Evidence of motion influencing surface oxygen ions can be seen in variable temperature measurements of the spin-lattice $\left(T_{1}\right)$ relaxation constant between room temperature and $200 \mathrm{~K}$ (Figure 7). The $T_{1}$ follows an Arrhenius temperature dependence, increasing with decreasing temperature, indicating motion slower than the Larmor frequency $(54.3 \mathrm{MHz}) .{ }^{41,42}$ To accurately determine the timescale of the motion, the $T_{1}$ minimum would have to be identified by increasing the measurement temperature, but raising the temperature would cause the surface to dehydrate, as previously demonstrated, so this is not possible. However, to effectively induce $T_{1}$ relaxation the motion must be on a similar timescale to the Larmor frequency, which is consistent with motion that is faster than the maximum peak separation of $6.5 \mathrm{kHz} .{ }^{43}$ From the gradient, an activation energy for the motion of $0.17 \mathrm{eV}$ can be extracted, this is a relatively low energy barrier, suggesting that the motion of water on the ceria (111) facets is facile and there is only weak interaction between the surface and these adsobred water molecules. It can be expected that, at water coverages less than 1 monolayer, the water molecules on the surface are generally isolated and the barrier for water migration is only slightly affected by the water coverage; therefore, the model $\mathrm{O}_{\mathrm{M} 1}$ (water coverage: $1 / 4$ monolayer) was chosen to calculate the energy barrier for water migration. Based on such model, an activation energy of $0.29 \mathrm{eV}$ is obtained for water migration from one surface $\mathrm{Ce}$ site to its adjacent surface $\mathrm{Ce}$ site (dominated by breaking of the $\mathrm{Ce}-\mathrm{OH}_{2}$ bond), which is comparable to the experimental value, but slightly higher. This may be ascribed to the stabilization of the transition state (Figure S19) by additional hydrogen bonding at water coverages higher than 1 monolayer, which is not captured in the calculation of the $\mathrm{O}_{\mathrm{M} 1}$ model. 


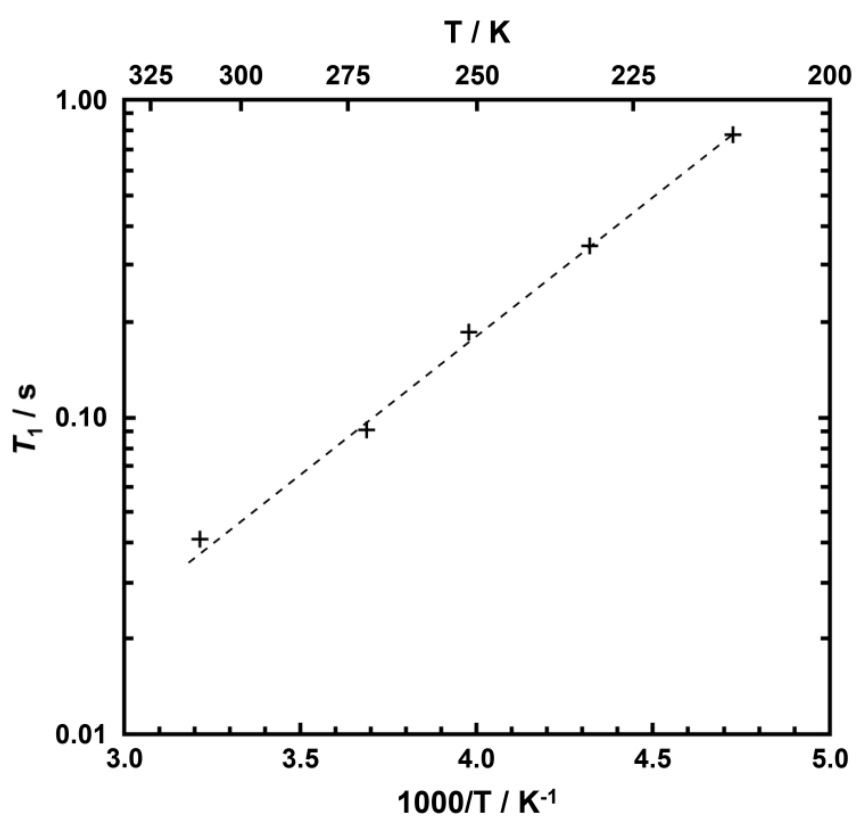

Figure 7. Arrhenius plot of the ${ }^{17} \mathrm{O} T_{1}$ constant for the $894 \mathrm{ppm}$ signal of NRs-RT, recorded at $9.4 \mathrm{~T}$ and 12.5 kHz MAS with a saturation recovery pulse sequence and rotor synchronized Hahn-echo detection $(\pi / 2-\tau-\pi-\tau$-acquisition, $\tau=1$ rotor-period $)$.

Having demonstrated the information that can be extracted from surface ${ }^{17} \mathrm{O}$ NMR spectra, we compare different strategies for surface selectivity, namely surface-selective enrichment and DNP. Surface-selective enrichment $^{15,22}$ is realized by fast exchange between the high concentration of the isotope being introduced and the low concentration of the natural isotope, with low temperatures being used to preclude diffusion into the bulk. In contrast, DNP techniques achieve surface selectivity because the biradicals are external to the sample and the hyperpolarization mechanism has a $1 / r^{6}$ distance dependence, so that surface nuclei are selectively hyperpolarized, enhancing their NMR signals. ${ }^{25,44}$ Figure 8 shows a comparison of these methods for ceria nanorods: For the conventional ${ }^{17} \mathrm{O}$ NMR spectrum of natural abundance (N.A.) ceria nanorods (Figure 8A), only the sharp bulk peak at $877 \mathrm{ppm}$ can be observed, while the N.A. direct DNP ${ }^{17} \mathrm{O}$ NMR spectrum (Figure 8C) exhibits an additional shoulder at around 894 ppm related to surface oxygen sites. In contrast, for the selectively enriched sample, the surface environments can be distinguished in the 
conventional NMR spectrum (Figure 8B), while the direct DNP NMR spectrum (Figure 8D) has a lower resolution due to both the limitation in spinning speed and the increased linewidth of surface signals at low temperature. However, indirect ${ }^{1} \mathrm{H} \rightarrow{ }^{17} \mathrm{O}$ DNP NMR (Figure 3) can be used to measure signals related to surface proton species, which are absent in the corresponding conventional ${ }^{17} \mathrm{O}$ NMR spectrum (Figure 1), due to the large enhancement of indirect DNP. In conclusion, to measure the NMR spectrum of oxygen ions on the surface, the technique of choice depends on the cost and feasibility of the isotopic labeling, as well as the presence of ${ }^{1} \mathrm{H}$ nuclei from which cross-polarization can be achieved: for poorly enriched or N.A. samples, direct DNP is more favorable, and if indirect DNP can be performed, it can give very high enhancements; however, for materials which can be readily surface labeled, especially those without abundant ${ }^{1} \mathrm{H}$ nuclei near the surface, or for which the nuclei of interest is challenging to cross-polarize (i.e. quadrupolar nuclei such as ${ }^{17} \mathrm{O}$ ), surface-selective enrichment combined with conventional NMR spectroscopy may yield the best results. 
(A) Conventional NMR
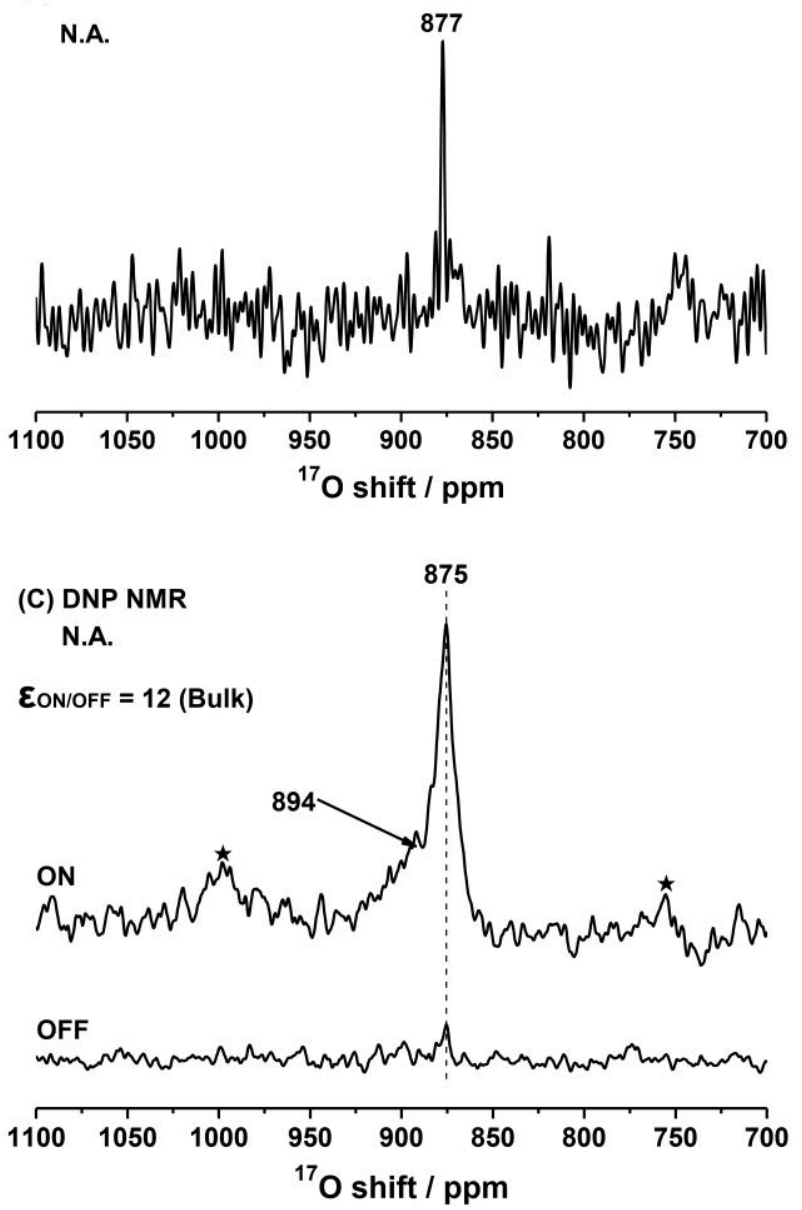

(B) Conventional NMR

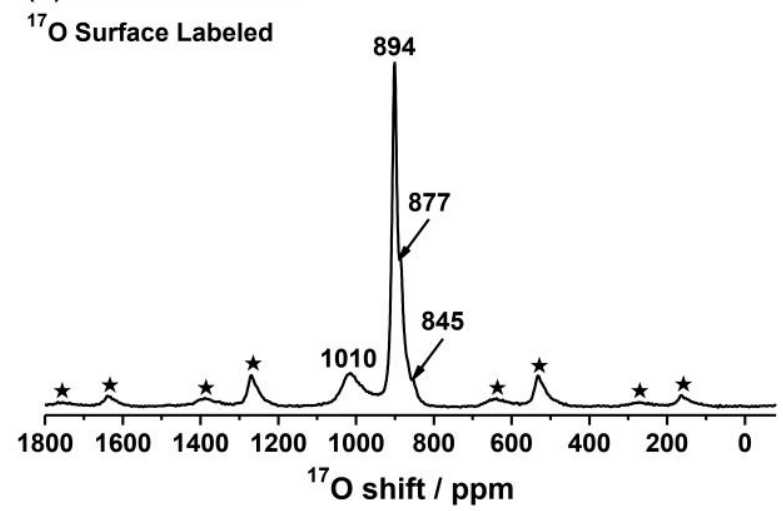

(D) DNP NMR

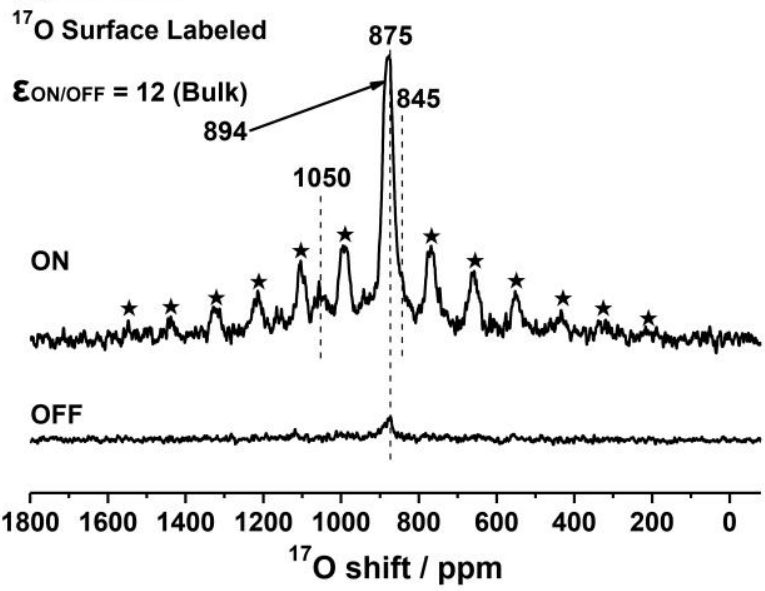

Figure 8. Conventional ${ }^{17} \mathrm{O}$ NMR spectra of (A) N.A. ceria nanorods and (B) NRs-RT, compared to their direct DNP spectra (C and D) with and without microwave irradiation. The spectra were recorded at spinning speeds of $20.0 \mathrm{kHz}$ for (A and B), $13.9 \mathrm{kHz}$ for (C), and $9.0 \mathrm{kHz}$ for (D). A pre-saturated rotor synchronized Hahn-echo pulse sequence $(\pi / 2-\tau-\pi-\tau-$ acquisition) was used for the conventional (A, B) and DNP spectra (C, D) respectively. Asterisks denote spinning sidebands.

\section{CONCLUSION}

${ }^{17} \mathrm{O}$ and ${ }^{1} \mathrm{H}$ solid-state NMR spectroscopy, combined with DFT simulations, have been utilized to investigate the structure and water-solid interactions of hydrated ceria (111) surfaces. The results presented here show that the hydrated surfaces consist of three different environments: bare terminal first layer oxygen ions, first layer oxygen ions coordinated to water molecules, and surface hydroxyl species formed from water 
dissociation. By investigating the ${ }^{17} \mathrm{O}$ NMR shifts as a function of the heat treatment temperature, as well as performing variable temperature ${ }^{17} \mathrm{O}$ relaxometry, highly dynamic water molecules are found to be present and instantaneously coordinate to the surface oxygen ions. These results show that ${ }^{17} \mathrm{O}$ MAS NMR is an ideal probe with high sensitivity to study hydrated surfaces, illustrating the complex nature of interactions between oxides and water. DNP NMR spectra supplement the ${ }^{17} \mathrm{O}$ spectral assignments; however, by comparing isotopic labeling and DNP techniques for the study of surfaces, we conclude that the optimal technique depends on the feasibility of enrichment and the presence of protons in the sample. In this work, to determine the impact of water on ceria surfaces, isotopic labeling and conventional NMR prove more successful, while the detection of surface protonated species (molecular adsorbed water and surface hydroxyl groups) benefit greatly from DNP techniques. The methodology presented in this work can be used to study the water-solid interactions of other hydrated materials.

\section{EXPERIMENTAL SECTION}

\section{Synthesis of ceria nanorods}

$1.96 \mathrm{~g} \mathrm{Ce}\left(\mathrm{NO}_{3}\right)_{3} \cdot 6 \mathrm{H}_{2} \mathrm{O}$ (Sigma Aldrich, $99.999 \%$ ) was dissolved in $40 \mathrm{~mL}$ deionized water and stirred for $10 \mathrm{~min}$. The solution was mixed with $30 \mathrm{~mL}$ aqueous $\mathrm{NaOH}(\mathrm{pH}=14)$ before continuing stirring for $30 \mathrm{~min}$, followed by heating at $100{ }^{\circ} \mathrm{C}$ for $24 \mathrm{~h}$ in a hydrothermal reactor. The reactor was then cooled down to room temperature and a yellow sediment was obtained. Subsequently, the sediment was centrifuged, washed with deionized water and dried at $100{ }^{\circ} \mathrm{C}$ for $12 \mathrm{~h}$. Finally, the sediment was calcined in a tube furnace at $700{ }^{\circ} \mathrm{C}$ for $5 \mathrm{~h}$ in flowing oxygen gas to yield ceria nanorods (NRs). ${ }^{45}$

\section{Characterization}

Powder X-Ray Diffraction (XRD) was performed with a Philips X'Pro X-ray diffractometer with $\mathrm{Cu} \mathrm{K} \alpha$ 
irradiation $(\lambda=1.54184 \AA)$ at $40 \mathrm{kV}$ and $40 \mathrm{~mA}$. High-Resolution Transmission Electron Microscope (HRTEM) images were acquired on a JEOL JEM-2010 system with an acceleration voltage of $200 \mathrm{kV}$. X-ray Photoelectron Spectra (XPS) were recorded on a Thermo ESCALAB $250 \mathrm{X}$ instrument with an excitation source of $\mathrm{Al} \mathrm{K} \alpha(\mathrm{h} v=1486.6 \mathrm{eV})$. The binding energies were referenced to $\mathrm{C} 1 \mathrm{~s}$ at $284.8 \mathrm{eV}$. Brunaure-Emmett-Teller (BET) specific surface area data was measured with nitrogen adsorption at $-196{ }^{\circ} \mathrm{C}$ on a Micromeritics ASAP 2020 instrument. Raman spectra were recorded on a Bruker Multi RAM FT-Raman spectrometer utilizing the $514 \mathrm{~nm}$ light of a He-Ne laser. The content of $\mathrm{Na}$ ions was determined with an Optima 5300DV inductively coupled plasma mass spectrometer (ICP-MS) while the content of N species was analyzed on a Heraeus CHN-0-Rapid elemental analyzer.

\section{Process of ${ }^{17} \mathrm{O}$ Isotopic Labeling}

In a typical ${ }^{17} \mathrm{O}$ isotopic labeling procedure, a quartz tube was filled with $180 \mathrm{mg}$ sample, calcined at $300{ }^{\circ} \mathrm{C}$ under $1 \times 10^{-3}$ Torr for $4 \mathrm{~h}$ to remove surface physisorbed water and hydroxyl groups, then cooled to room temperature (RT). For the ${ }^{17} \mathrm{O}_{2}$ enriched sample $\left(\mathrm{NRs}-{ }^{17} \mathrm{O}_{2}\right)$, commercial $90 \%{ }^{17} \mathrm{O}$-enriched $\mathrm{O}_{2}$ gas $(30$ mbar, Isotec Inc.) was introduced and the tube sealed before heating at $300{ }^{\circ} \mathrm{C}$ for $1 \mathrm{~h}$, followed by evacuating the tube at $10^{-3}$ Torr for $5 \mathrm{~min}$. The $\mathrm{H}_{2}{ }^{17} \mathrm{O}$ enriched samples were exposed to $90 \%{ }^{17} \mathrm{O}$-enriched $\mathrm{H}_{2} \mathrm{O}$ vapour (Isotec Inc., $30 \mathrm{mbar}$ ) in a sealed tube for $1 \mathrm{~h}$ at RT, followed by drying under vacuum at $10^{-3}$ Torr at specific temperatures in order to remove any physisorbed $\mathrm{H}_{2}{ }^{17} \mathrm{O}\left(\mathrm{RT}, 40{ }^{\circ} \mathrm{C}, 60{ }^{\circ} \mathrm{C}, 80{ }^{\circ} \mathrm{C}, 100{ }^{\circ} \mathrm{C}\right.$ and $150{ }^{\circ} \mathrm{C}$, abbreviated as NRs-T, where T represents the drying temperature in degree Celsius). An additional sample was prepared by re-enriching the NRs-100 with $\mathrm{H}_{2}{ }^{17} \mathrm{O}$ at room temperature and then re-evacuating it at room temperature (abbreviated as NRs-100 $\rightarrow$ RT).

\section{Solid-State NMR Spectroscopy}


${ }^{17} \mathrm{O}$ and ${ }^{1} \mathrm{H}$ Magic Angle Spinning Nuclear Magnetic Resonance (MAS NMR) measurements were performed at Larmor frequencies of 54.2 and 400.0 MHz, respectively, on a 9.4 T Bruker Avance III 400 spectrometer. Samples were packed into $3.2 \mathrm{~mm}$ laser marked $\mathrm{ZrO}_{2}$ rotors within a $\mathrm{N}_{2}$-filled glove box. ${ }^{17} \mathrm{O}$ and ${ }^{1} \mathrm{H}$ chemical shifts were referenced to $\mathrm{H}_{2} \mathrm{O}$ at $0.0 \mathrm{ppm}$ and to adamantane at $1.92 \mathrm{ppm}$, respectively.

${ }^{17} \mathrm{O}$ dynamic nuclear polarization (DNP) NMR experiments were recorded on a Bruker Avance III HD 600 spectrometer equipped with a $395 \mathrm{GHz}$ gyrotron microwave source and an $89 \mathrm{~mm}$ wide-bore $14.1 \mathrm{~T}$ superconducting magnet, yielding a Larmor frequency of $81.3 \mathrm{MHz}$. A microwave source power of $7.0 \mathrm{~W}$ was used for the ${ }^{17} \mathrm{O}$ DNP experiments. Samples were mixed with radical solution $\left(16 \mathrm{mM}\right.$ TEKPol ${ }^{46}$ in dried TCE) inside a $\mathrm{N}_{2}$-filled glove box before packing into $3.2 \mathrm{~mm}$ rotors. The ${ }^{17} \mathrm{O}$ chemical shifts in DNP NMR spectra were referenced to bulk ceria at $875 \mathrm{ppm}$ at $100 \mathrm{~K}$. The temperature of low temperature NMR experiments was determined using an ex-situ calibration with the ${ }^{207} \mathrm{~Pb}$ shift of $\mathrm{Pb}\left(\mathrm{NO}_{3}\right)_{2} \cdot{ }^{47}$

\section{Details of DFT Calculations}

Spin-polarized DFT calculations were performed with the Vienna Ab initio Simulation Package (VASP), using the Perdew-Burke-Ernzerhof $(\mathrm{PBE})$ functional $^{49}$ with a Hubbard $U$ correction $(\mathrm{PBE}+U){ }^{50}$ The effective $U$ value applied to the localized Ce $4 f$ orbitals was set to $5.0 \mathrm{eV}^{51,52}$ This computational setup has been shown to be capable of producing results in excellent agreement with experimental observations. ${ }^{22,26}$ The interaction between core and valence electrons was described with the projector augmented wave (PAW) method. $^{53}$ A plane-wave kinetic energy cutoff of $500 \mathrm{eV}$ was used for all calculations. Geometry optimizations were finished when the Hellman-Feynman force on each relaxed ion was less than 0.02 $\mathrm{eV} \cdot \AA^{-1}$. The convergence criterion for electronic minimization was $10^{-5} \mathrm{eV}$ for geometry optimizations and was $10^{-8} \mathrm{eV}$ for chemical shift and electric field gradient (EFG) calculations. ${ }^{22,26}$ The optimized lattice 
parameter of ceria was $5.448 \AA$, in agreement with the experimental value of $5.411 \AA .^{54}$

The (111) surface of ceria was modeled by a 12-oxygen-layer surface slab (i.e., six O-Ce-O tri-layers) with a $(2 \times 2)$ surface cell (area: $\left.7.7 \AA \times 7.7 \AA \times \sin 60^{\circ}=51.3 \AA^{2}\right)$; the surface slab was found to be thick enough since the middle layers of this model reproduce the bulk experimental chemical shift. ${ }^{22,26}$ The model contains a large vacuum gap (>10 $\AA$ ) along the [111] direction in order to eliminate slab-slab interactions. For geometry optimizations on hydrated ceria (111) surfaces, the bottom two $\mathrm{CeO}_{2}$ tri-layers were fixed. The DFT-D3 method of Grimme et al. ${ }^{55}$ was used to capture the dispersion interactions between water molecules and the ceria (111) surface. Reciprocal space for all calculations was sampled with a $2 \times 2 \times 1$ Monkhorst-Pack grid.

The average adsorption energies of $\mathrm{H}_{2} \mathrm{O}\left(E_{a d s}^{a v g}\right)$ of the hydrated ceria (111) surfaces were calculated as follows:

$$
E_{\text {ads }}^{a v g}=\frac{1}{n}\left\{E\left[n \mathrm{H}_{2} \mathrm{O} / \mathrm{CeO}_{2}\right]-E\left[\mathrm{CeO}_{2}\right]-n E\left[\mathrm{H}_{2} \mathrm{O}\right]\right\}
$$

where $n$ is the number of adsorbed water molecules, $E\left[\mathrm{nH}_{2} \mathrm{O} / \mathrm{CeO}_{2}\right], E\left[\mathrm{CeO}_{2}\right]$, and $E\left[\mathrm{H}_{2} \mathrm{O}\right]$ are the calculated total energies of the adsorption complex, the ceria substrate, and the gas phase $\mathrm{H}_{2} \mathrm{O}$ molecule, respectively. The climbing-image nudged elastic band (CI-NEB) method was used to locate the transition state structure of water migration. ${ }^{56,57}$

The ${ }^{17} \mathrm{O}$ NMR parameter calculations were performed as described in our previous work. ${ }^{22,26}$ To calculate the ${ }^{17} \mathrm{O}$ quadrupolar parameters $\left(C_{\mathrm{Q}}\right.$ and $\left.\eta\right)$, the experimental quadrupole moment $(Q)$ of -0.02558 barns ${ }^{58}$ for ${ }^{17} \mathrm{O}$ was utilized. The isotropic chemical shifts $\left(\delta_{i s o}\right)$ were calculated according to

$$
\delta_{i s o}=\delta_{c a l}+\delta_{r e f},
$$


where $\delta_{c a l}$ represents the unaligned DFT chemical shift and $\delta_{r e f}$ is the reference chemical shift. For all slab models studied, the average value of the unaligned ${ }^{17} \mathrm{O}$ DFT chemical shifts in the bulk-like layers $(\mathrm{O}$ layers $4-9$ ) is $830 \mathrm{ppm}$; by aligning this value to the experimental ${ }^{17} \mathrm{O}$ shift of $877 \mathrm{ppm}$ for bulk oxygen ions, a $\delta_{\text {ref }}$ of $47 \mathrm{ppm}$ was obtained (Figures S11, S14, and S17).

\section{ASSOCIATED CONTENT}

\section{Supporting Information}

Characterization data, experimental NMR spectra, and DFT computational data. This material is available free of charge via the Internet at http://pubs.acs.org.

\section{AUTHOR INFORMATION}

\section{Corresponding Authors}

*xpwu@ecust.edu.cn

*cpg27@cam.ac.uk

*luming@nju.edu.cn

\section{Author Contributions}

$\dagger$ These authors contributed equally.

\section{Notes}

The authors declare no competing financial interest.

\section{ACKNOWLEDGEMENTS}

This work was supported by the National Natural Science Foundation of China (NSFC) (21972066, 91745202, 21573103 and 21421004), NSFC - Royal Society Joint Program (21661130149), the 
Fundamental Research Funds for the Central Universities (1124020512) and National Science Fund for

Talent Training in Basic Science (J1103310). Xin-Ping Wu thanks the Research Start-up Fund for

Distinguished Research Fellow at East China University of Science and Technology (ECUST) under Award No. YJ0142208. The ECUST group thanks the Programme of Introducing Talents of Discipline to Universities (B16017). Luming Peng thanks the Royal Society and Newton Fund for a Royal Society Newton Advanced Fellowship. Clare P. Grey thanks the European Research Council for an Advanced Fellowship. This work was also supported by a Project Funded by the Priority Academic Program Development of Jiangsu Higher Education Institutions. Michael A. Hope would like to thank the Oppenheimer foundation for funding. David M. Halat acknowledges the Cambridge International Trust for funding, and is grateful for support from NECCES, an Energy Frontier Research Center funded by the U.S. Department of Energy, Office of Science, Office of Basic Energy Sciences under Award No. DE-SC0012583. We would like to thank Dr. Subhradip Paul in University of Nottingham for invaluable discussions and help in this work.

\section{REFERENCES}

(1) Brown, G. E.; Henrich, V. E.; Casey, W. H.; Clark, D. L.; Eggleston, C.; Felmy, A.; Goodman, D. W.; Grätzel, M.; Maciel, G.; McCarthy, M. I.; Nealson, K. H.; Sverjensky, D. A.; Toney, M. F.; Zachara, J. M. Metal oxide surfaces and their interactions with aqueous solutions and microbial organisms. Chem. Rev. 1999, 99, 77-174.

(2) Chen, G.; Zhao, Y.; Fu, G.; Duchesne, P. N.; Gu, L.; Zheng, Y.; Weng, X.; Chen, M.; Zhang, P.; Pao, C. -W.; Lee, J. -F.; Zheng, N. Interfacial effects in iron-nickel hydroxide-platinum nanoparticles enhance catalytic oxidation. Science 2014, 344, 495-500.

(3) Liu, L. M.; Mcallister, B.; Ye, H. Q.; Hu, P. Identifying an $\mathrm{O}_{2}$ supply pathway in $\mathrm{CO}$ oxidation on 
$\mathrm{Au} / \mathrm{TiO}_{2}(110)$ : a density functional theory study on the intrinsic role of water. J. Am. Chem. Soc. 2006, $128,4017-4022$.

(4) Tada, H.; Soejima, T.; Ito, S.; Kobayashi, H. Photoinduced desorption of sulfur from gold nanoparticles loaded on metal oxide surfaces. J. Am. Chem. Soc. 2004, 126, 15952-15953.

(5) Stamenkovic, V. R.; Strmcnik, D.; Lopes, P. P.; Markovic, N. M. Energy and fuels from electrochemical interfaces. Nat. Mater. 2016, 16, 57-69.

(6) Davis, J. A.; Hayes, K. F. Geochemical Processes at Mineral Surfaces: An Overview; American Chemical Society, 1987.

(7) Henderson, M. A. The interaction of water with solid surfaces: fundamental aspects revisited. Surf. Sci. Rep. 2002, 46, 1-308.

(8) VAN Westing, E. P. M.; Ferrari, G. M.; DE Wit, J. H. W. The determination of coating performance with impedance measurements - II. Water uptake of coatings. Corros. Sci. 1994, 36, 957-977.

(9) Guo, J.; Bian, K.; Lin, Z.; Jiang, Y. Perspective: Structure and dynamics of water at surfaces probed by scanning tunneling microscopy and spectroscopy. J. Chem. Phys. 2016, 145, 160901.

(10) Carrasco, J.; Hodgson, A.; Michaelides, A. A molecular perspective of water at metal interfaces. Nat. Mater. 2012, 11, 667-674.

(11) Mu, R.; Zhao, Z. -J.; Dohnálek, Z.; Gong, J. Structural motifs of water on metal oxide surfaces. Chem. Soc. Rev. 2017, 46, 1785-1806.

(12) Verdaguer, A.; Sacha, G. M.; Bluhm, H.; Salmeron, M. Molecular Structure of Water at Interfaces: Wetting at the nanometer scale. Chem. Rev. 2006, 106, 1478-1510.

(13) Halwidl, D.; Stöger, B.; Mayr-schmölzer, W.; Pavelec, J.; Fobes, D.; Peng, J.; Mao, Z.; Parkinson, G. S.; Schmid, M.; Mittendorfer, F. Redinger, J.; Diebold, U. Adsorption of water at the SrO surface of ruthenates. Nat. Mater. 2016, 15, 450-456. 
(14) Diebold, U.; Ruzycki, N.; Herman, G. S.; Selloni, A. One step towards bridging the materials gap: surface studies of $\mathrm{TiO}_{2}$ anatase. Catal. Today. 2003, 85, 93-100.

(15) Li, Y.; Wu, X. -P.; Jiang, N.; Lin, M.; Shen, L.; Sun, H.; Wang, Y.; Wang, M.; Ke, X.; Yu, Z.; Gao, F.; Dong, L.; Guo, X.; Hou, W.; Ding, W.; Gong, X. -Q.; Grey, C. P.; Peng, L. Distinguishing faceted oxide nanocrystals with ${ }^{17} \mathrm{O}$ solid-state NMR spectroscopy. Nat. Commun. 2017, 8, 581.

(16) Li, Y.; Wu, X. -P.; Liu, C.; Wang, M.; Song, B.; Yu, G.; Gang, Y.; Hou, W.; Gong, X. -Q.; Peng, L. NMR and EPR studies of partially reduced $\mathrm{TiO}_{2}$. Acta Phys. -Chim. Sin. 2020, 36, 1905021.

(17) Vogt, T.; Dahmen, W.; Binev, P. Modeling nanoscale imaging in electron microscopy; Springer, 2012.

(18) Wang, Y.; Wöll, C. IR spectroscopic investigations of chemical and photochemical reactions on metal oxides: bridging the materials gap. Chem. Soc. Rev. 2017, 46, 1875-1932.

(19) Kong, X.; Deng, H.; Yan, F.; Kim, J.; Swisher, J. A.; Smit, B.; Yaghi, O. M.; Reimer, J. A. Mapping of functional groups in metal-organic frameworks. Science 2013, 341, 882-885.

(20) Grey, C. P.; Dupré, N. NMR studies of cathode materials for lithium-ion rechargeable batteries. Chem. Rev. 2004, 104, 4493-4512.

(21) Ashbrook, S. E.; Smith, M. E. Solid state ${ }^{17}$ O NMR - an introduction to the background principles and applications to inorganic materials. Chem. Soc. Rev. 2006, 35, 718-735.

(22) Wang, M.; Wu, X. -P.; Zheng, S.; Zhao, L.; Li, L.; Shen, L.; Gao, Y.; Xue, N.; Guo, X.; Huang, W.; Gan, Z.; Blanc, F.; Yu, Z.; Ke, X.; Ding, W.; Gong, X. -Q.; Grey, C. P.; Peng, L. Identification of different oxygen species in oxide nanostructures with ${ }^{17} \mathrm{O}$ solid-state NMR spectroscopy. Sci. Adv. 2015, 1, e1400133.

(23) Du, J. H.; Peng, L. Recent progress in investigations of surface structure and properties of solid oxide materials with nuclear magnetic resonance spectroscopy. Chinese Chem. Lett. 2018, 29, 747-751. 
(24) Ni, Q. Z.; Daviso, E.; Can, T. V.; Markhasin, E.; Jawla, S. K.; Swager, T. M.; Temkin, R. J.; Herzfeld, J.; Griffin, R. G. High frequency dynamic nuclear polarization. Accounts Chem. Res. 2013, 46, 19331941.

(25) Hope, M. A.; Halat, D. M.; Magusin, P. C. M. M.; Paul, S.; Peng, L.; Grey, C. P. Surface-selective direct ${ }^{17} \mathrm{O}$ DNP NMR of $\mathrm{CeO}_{2}$ nanoparticles. Chem. Commun. 2017, 53, 2142-2145.

(26) Chen, J.; Wu, X. -P.; Hope, M. A.; Qian, K.; Halat, D. M.; Liu, T.; Li, Y.; Shen, L.; Ke, X.; Wen, Y.; Du, J. -H.; Magusin, P. C. M. M.; Paul, S.; Ding, W.; Gong, X. -Q.; Grey, C. P.; Peng, L. Polar surface structure of oxide nanocrystals revealed with solid-state NMR spectroscopy. Nat. Commun. 2019, 10, 5420 .

(27) Shen, L.; Wang, Y.; Du, J. -H.; Chen, K.; Lin, Z.; Wen, Y.; Hung, I.; Gan, Z.; Peng, L. Probing Interactions of $\gamma$-Alumina with water via multinuclear solid-state NMR spectroscopy. ChemCatChem 2020, 12, 1569-1574.

(28) Wu, X. -P; Gong, X. -Q.; Lu, G. Role of oxygen vacancies in the surface evolution of $\mathrm{H}$ at $\mathrm{CeO}_{2}(111)$ : a charge modification effect. Phys. Chem. Chem. Phys. 2015,17, 3544-3549.

(29) Rodriguez, J. A.; Ma, S.; P. Liu.; Hrbek, J.; Evans, J.; Pérez, M. Activity of $\mathrm{CeO}_{x}$ and $\mathrm{TiO}_{x}$ nanoparticles grown on $\mathrm{Au}(111)$ in the water-gas shift reaction. Science 2007, 318, 1757-1760.

(30) Wu, X. -P; Gong, X. -Q. Unique electronic and structural effects in Vanadia/Ceria-catalyzed reactions. J. Am. Chem. Soc. 2015, 137, 13228-13231.

(31) Carrettin, S.; Concepción, P.; Corma, A.; Nieto, J. M. L.; Puntes, V. F. Nanocrystalline $\mathrm{CeO}_{2}$ increases the activity of $\mathrm{Au}$ for $\mathrm{CO}$ oxidation by two orders of magnitude. Angew. Chem. Int. Ed. 2004, 43, $2538-2540$.

(32) Kašpar, J.; Fornasiero, P.; Graziani, M. Use of $\mathrm{CeO}_{2}$-based oxides in the three-way catalysis. Catal. Today 1999, 50, 285-298. 
(33) Mogilevsky, G.; Karwacki, C. J.; Peterson, G. W.; Wagner, G. W. Surface hydroxyl concentration on $\mathrm{Zr}(\mathrm{OH})_{4}$ quantified by ${ }^{1} \mathrm{H}$ MAS NMR. Chem. Phys. Lett. 2011, 511, 384-388.

(34) Freude, D.; Hunger, M.; Pfeifer, H.; Schwieger, W. ${ }^{1}$ H NMR studies on the acidity of zeolites. Chem. Phys. Lett. 1986, 128, 62-66.

(35) Kazuhiko Y.; Kenzo D.; Tadashi S; Junji W. Line-shape analyses of solid-state ${ }^{17}$ O NMR spectra for hexagonal ice. Z. Naturforsch. 2014, 69b, 786-792.

(36) Gullion, T. Introduction to rotational-echo, double-resonance NMR. Concept. Magn. Reso. 1998, 10, 277-289.

(37) Peng, L.; Kim, N.; Readman, J.; Grey, C. P. Detection of Brønsted acid sites in zeolite HY with high-field ${ }^{17}$ O-MAS-NMR techniques. Nat. Mater. 2005, 4, 216-219.

(38) Peng, L.; Huo, H.; Liu, Y.; Grey, C. P. ${ }^{17} \mathrm{O}$ magic angle spinning NMR studies of Brønsted acid sites in zeolites HY and HZSM-5. J. Am. Chem. Soc. 2007, 129, 335-346.

(39) Matsuoka, S.; Inoue, M. Application of REDOR NMR in natural product chemistry. Chem. Commun. 2009, 38, 5664-5675.

(40) Kropp, T.; Paier, J.; Sauer, J. Interactions of water with the (111) and (100) surfaces of ceria. J. Phys. Chem. C 2017, 121, 21571-21578.

(41) Levitt, M. H. Spin Dynamics: Basics of Nuclear Magnetic Resonance; John Wiley \& Sons, 2018.

(42) Hope, M. A.; Halat, D. M.; Lee, J.; Grey, C. P. A ${ }^{17}$ O paramagnetic NMR study of $\mathrm{Sm}_{2} \mathrm{O}_{3}, \mathrm{Eu}_{2} \mathrm{O}_{3}$, and Sm/Eu-substituted $\mathrm{CeO}_{2}$. Solid State Nuclear Magnetic Resonance 2019, 102, 21-30.

(43) Fuda, K.; Kishio, K.; Yamauchi, S.; Fueki, K. ${ }^{17} \mathrm{O}$ NMR study of $\mathrm{Y}_{2} \mathrm{O}_{3}$-doped $\mathrm{CeO}_{2}$. J. Phy. Chem. Solids 1984, 45, 1253-1257.

(44) Berruyer, P.; Emsley, L.; Lesage, A. DNP in materials science: Touching the surface. eMagRes 2018, 7, 93-104. 
(45) Gao, Y.; Li, R.; Chen, S.; Luo, L.; Cao, T.; Huang, W. Morphology-dependent interplay of reduction behaviors, oxygen vacancies and hydroxyl reactivity of $\mathrm{CeO}_{2}$ nanocrystals. Phys. Chem. Chem. Phys. 2015, 17, 31862-31871.

(46) Zagdoun, A.; Casano, G.; Ouari, O.; Schwarzwälder, M.; Rossini, A. J.; Aussenac, F.; Yulikov, M.; Jeschke, G.; Copéret, C.; Lesage, A.; Tordo, P.; Emsley, L. Large molecular weight nitroxide biradicals providing efficient dynamic nuclear polarization at temperatures up to $200 \mathrm{~K}$. J. Am. Chem. Soc. 2013, 135, 12790-12797.

(47) Bielecki, A.; Burum, D. P. Temperature dependence of ${ }^{207} \mathrm{~Pb}$ MAS spectra of solid lead nitrate. An accurate, sensitive thermometer for variable-temperature MAS. J. Magn. Reson. 1995, 116, 215-220.

(48) Kresse, G.; Hafner, J. Ab initio molecular-dynamics simulation of the liquid-metal-amorphous-semiconductor transition in germanium. Phys. Rev. B 1994, 49, 1425114269.

(49) Perdew, J. P.; Burke, K.; Ernzerhof, M. Generalized gradient approximation made simple. Phys. Rev. Lett. 1996, 77, 3865-3868.

(50) Dudarev, S. L.; Botton, G. A.; Savrasov, S. Y.; Humphreys, C. J.; Sutton, A. P. Electron-energy-loss spectra and the structural stability of nickel oxide: An LSDA+U study. Phys. Rev. B 1998, $57,1505-$ 1509.

(51) Nolan, M.; Parker, S. C.; Watson, G. W. The electronic structure of oxygen vacancy defects at the low index surfaces of ceria. Surf. Sci. 2005, 595, 223-232.

(52) $\mathrm{Wu}, \mathrm{X}$. -P; Gong, X. -Q. Clustering of oxygen vacancies at $\mathrm{CeO}_{2}(111)$ : Critical role of hydroxyls. Phys. Rev. Lett. 2016, 116, 086102.

(53) Blöchl, P. E. Projector augmented-wave method. Phys. Rev. B 1994, 50, 17953-17979.

(54) Kümmerle, E. A.; Heger, G. The structures of $\mathrm{C}_{-} \mathrm{Ce}_{2} \mathrm{O}_{3+\delta}, \mathrm{Ce}_{7} \mathrm{O}_{12}$, and $\mathrm{Ce}_{11} \mathrm{O}_{20}$. J. Solid State Chem. 
1999, $147,485-500$.

(55) Grimme, S.; Antony, J.; Ehrlich, S.; Krieg, H. A consistent and accurate ab initio parametrization of density functional dispersion correction (DFT-D) for the 94 elements H-Pu. J. Chem. Phys. 2010, 132, 154104.

(56) Henkelman, G.; Uberuaga, B. P.; Jónsson, H. A climbing image nudged elastic band method for finding saddle points and minimum energy paths. J. Chem. Phys. 2000, 113, 9901-9904.

(57) Henkelman, G.; Jónsson, H. Improved tangent estimate in the nudged elastic band method for finding minimum energy paths and saddle points. J. Chem. Phys. 2000, 113, 9978-9985.

(58) Sundholm, D.; Olsen, J. Finite element multiconfiguration Hartree-Fock calculations on carbon, oxygen, and neon: The nuclear quadrupole moments of ${ }^{11} \mathrm{C},{ }^{17} \mathrm{O}$, and ${ }^{21} \mathrm{Ne} . J$. Phys. Chem. 1992, 96, $627-630$. 
FOR TABLE OF CONTENTS ONLY

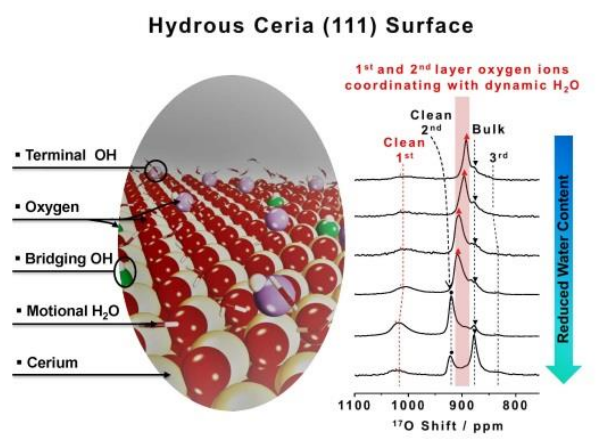

